Dept. of Theriogenology,

Faculty of Veterinary Medicine, Beni-Suef University

\title{
SUCCESSFUL PRODUCTION OF BUFFALO EMBRYOS FROM VITRIFIED IMMATURE AND MATURE OOCYTES IN VITRO
}

(With One Table and 4 Figures)

By

\section{S.M. ABD-ALLAH; A. GOMAA; E.M.M. ABD-EL-GAWAD and E.M. EL-NAHAS*}

*Dept. of Cell Biology, National Researcher Center, Dokki, Egypt.

(Received at 2/4/2009)

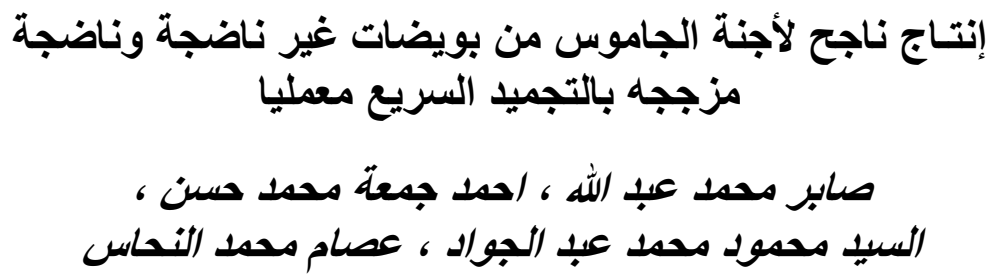

تهدف الدر اسة الحالية إلى إنتاج أجنة الجاموس معمليا من بويضات غير ناضجة ولئات وناضجة







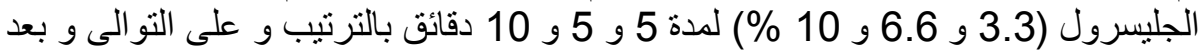





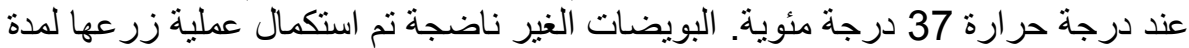

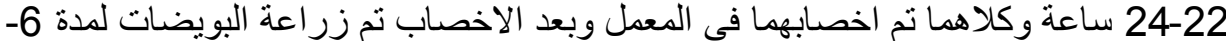

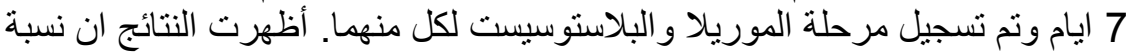




عنها من البويضات الغير ناضجة (10.3 \% \% و و 2.6 \% على التو الى).

\section{SUMMARY}

The current study was conducted to produce buffalo embryos in vitro from vitrified immature and mature oocytes. Cumulus oocytes complexes (COCs) were obtained from ovaries which collected from a local abattoir. 
Good quality COCs (immature oocytes) were vitrified immediately after collection. After 22-24 hours of COCs culture, mature oocytes were vitrified similarly.

All oocytes (immature and mature) were exposed to vitrification solution of different concentrations (glycerol: 3.3, 6.6 and 10\%) at 5, 5 and 10 minutes intervals respectively. The oocytes were finally placed in $10 \%$ glycerol and immediately loaded in $0.25 \mathrm{ml}$ plastic straws, each containing $100 \mu \mathrm{l}$ of $10 \%$ sucrose in Modified phosphate buffer saline (M-PBS).

The straws were stored in liquid nitrogen for 4-6 months. The straws were thawed in water at $37^{\circ} \mathrm{C}$ for 30 seconds. After thawing, immature oocytes have been exposed to further maturation for 22-24 h. Mature oocytes were fertilized with frozen-thawed semen capacitated in modified fertilization TALP medium. After insemination, the oocytes were cultured for 6-7 days and the frequency of morula and/or blastocyst was recorded. Data analysis revealed that, the proportion of buffalo oocytes found to be normal after vitrification-thawing procedures was significantly different between immature and mature oocytes $(55.4 \%$ and $70.6 \%$ respectively) and a significantly higher $(\mathrm{p}<0.05)$ percentage of embryos development (morula and blastocyst) was derived from vitrified mature buffalo oocytes than those obtained from immature ones $(10.3 \%$ Vs. 2.6\%).

Key words: Buffalo, Embryos, Cryopreservation, Oocytes

\section{INTRODUCTION}

Cryopreservation method is a key factor in commercial embryo production and transfer technology, in addition offers the opportunity to implement novel animal breeding and production programs (Martinez, et al., 1999).

Several cryopreservation methods such as conventional (slow), equilibrium rapid freezing (vitrification) and ultra rapid freezing have been used to preserve embryos and oocytes of many animal species resulting in the birth of live offspring (Kajihara et al., 1992). Vitrification which is relatively recent approach defined as physical process by which a highly concentrated solution of cryoprotectants solidifies during cooling, without formation of ice crystals (Niemann, 1991). This offers several advantages over conventional equilibrium methods e.g. faster and simplified freezing and thawing procedures, high oocytes/embryos survival and no requirements for a freezing machine 
(Dhali, et al., 1999). Vitrification was reported to be suitable for cryopreservation of bovine oocytes (Hurrt, et al, 1999) and buffalo oocytes (Abd Allah 2003 and Badr et al., 2008).

Badr, et al. (2008) examined freezing sensitivity of immature buffalo oocytes frozen by vitrification in different ethylene glycol concentrations $(10,20$ and $40 \%)$ in the equilibration solution, equilibration periods (3,5 and $10 \mathrm{~min}$ ) and vitrification solutions (ethylene glycol with $0.5 \mathrm{M}$ sucrose, $0.3 \mathrm{M}$ trehalose and 20\% dimethyl sulfoxide). Of all oocytes frozen, nothing had developed blastocysts.

The present study was conduct to produce buffalo embryos from vitrified immature and mature oocytes.

\section{MATERIALS and METHODS}

All materials were purchased from Sigma Chemical Company (St. Louis, MO, USA) unless otherwise indicated.

\section{Collection of oocytes}

During period of the study (from winter of 1998 till winter of 2003), buffaloes ovaries were collected from a local abattoir and transported to the laboratory within $3-4 \mathrm{~h}$ in warm $\left(25^{\circ} \mathrm{C}\right)$ physiological saline containing $50 \mu \mathrm{g} / \mu \mathrm{l}$ gentamycin sulfate. COCs were recovered by aspiration of follicle 2-6 mm dimeter using an $18 \mathrm{G}$ needle attached to $10 \mathrm{ml}$ syringe. Only oocytes with at least three layers of compact cumulus cells and homogenous cytoplasm were selected, as described by Ganguli, et al. (1998).

\section{Expermental designe}

Buffalo oocytes were vitrified immediately after collection (immature oocytes) or vitrified after culture (mature oocytes, 24 h postcultured). Fresh oocytes without vitrification undergoing the same maturation and fertilization protocols were used as control.

\section{In vitro maturation}

Selected COCs were washed three times with pre-equilibrated maturation medium (TCM-199) supplemented with $10 \%$ heat inactivated fetal calf serum (FCS), $50 \mu \mathrm{g} / \mathrm{ml}$ gentamycin sulfate. COCs with unexpanded cumulus cells and evenly granulated ooplasm were cultured in $50 \mu \mathrm{l}$ drops (10 oocytes/droplet) of the same medium. The droplets were covered with sterile Millipore filtered mineral oil, pre-incubated under the maturation conditions for a minimum of $3 \mathrm{~h}\left(39^{\circ} \mathrm{C}, 5 \% \mathrm{CO}_{2}\right.$ in air with $95 \%$ relative humidity) and then incubated for $22-24 \mathrm{~h}$ (Totey, 
at al., 1993). The oocytes were assessed for maturation by cumulus mass expansion (Nandi, et al., 2002).

\section{Vitrification of oocytes}

The vitrification solution consisted of different concentrations of glycerol (3.3, 6.6 and 10\%) dissolved in M-PBS enriched with 10\% FCS and antibiotics. At room temperature, the oocytes (either immature or mature oocytes) were suspended in vitrification solution in concentrations 3.3; 6.6 and $10 \%$ in 3 steps at 5, 5, 10 minute's interval respectively. During equilibration for 5 minutes in the final solution (10\% glycerol) about $10-15$ oocytes were loaded in mini straws $(0.25$ ml) as previously described by Curtis (1991). The straws were sealed with hot sealer and pre cooled by keeping them in liquid nitrogen tank.

After storage for 4-6 month, the straws were warmed rapidly by transferring them to a water bath at $37^{\circ} \mathrm{C}$ for 30 seconds. The contents were expelled into an empty plastic sterile dish and the oocytes were allowed a 5 minutes equilibrium in 10\% sucrose solution in M-PBS for one step dilution.

The oocytes were then transferred to fresh washing medium (TCM-199 plus 10\% FCS with $50 \mu \mathrm{g} / \mu \mathrm{l}$ gentamycin sulfate) and were washed 3 times with it. The frozen-thawed oocytes (immature) were further incubated for $24 \mathrm{~h}$ in $\mathrm{CO}_{2}$ incubator under the same condition.

\section{Survival of oocytes after vitrification-thawing procedures}

Oocyte normality was evaluated according to Dhali, et al. (1999) by their post-thaw morphological appearance under stereo microscope. The criteria used for assessing morphology were as follow: normal oocytes with spherical and symmetrical shape with no sign of lysis, membrane damage, swelling, degeneration or leakage of the cellular content; abnormal oocytes with a ruptured zona pellucida or having fragmented cytoplasm with signs of degeneration.

\section{In vitro fertilization:}

Spermatozoa were prepared from frozen-thawed buffalo bull semen as described by Jaakma et al. (1995). The contents of two mini straws $(0.25 \mathrm{ml})$ were thawed in a water bath at $37^{\circ} \mathrm{C}$ for 30 seconds and pooled in a sterile warm tube. Thawed semen was layered, in six conical sterile tissue culture tubes, under $1.0 \mathrm{ml}$ of modified sperm-Tyroid's albumin lactate pyruvate (mS-TALP; S-TALP supplemented with 200 $\mathrm{IU} / \mathrm{ml}$ heparin sodium salt) medium for sperm capacitation. The tubes were held at angle of 45 degree for one hour at $39^{\circ} \mathrm{C}$. The uppermost supernatant $(200 \mu \mathrm{l})$ of each tube containing highly motile spermatozoa was obtained as well as pooled in a sterile $15 \mathrm{ml}$ centrifuge tube and then 
centrifuged at $1800 \mathrm{rpm}$ for 10 minutes. The pelleted spermatozoa were re-suspended in a sufficient amount of modified fertilization-TALP (mFTALP) to yield a final concentration of $2 \times 10^{6}$ sperm cells $/ \mathrm{ml}$.

Oocytes having expanded cumulus cells were washed 3 times in modified F-TALP medium. Then, placed in $50 \mu$ droplets of modified F-TALP (5 oocytes/droplet) and covered with warm sterile Millipore filtered mineral oil and incubated for one hour under the same gas atmosphere as for IVM. Insemination was then performed using 2 $\mu \mathrm{l} /$ droplet of capacitated sperm. The co-cultured oocytes were incubated at $39^{\circ} \mathrm{C}, 5.0 \% \mathrm{CO}_{2}$ and $95 \%$ relative humidity during $24 \mathrm{~h}$ for fertilization.

The presumptive zygotes were denuded of surrounding cumulus cells by washing 3 times using TCM-199 medium supplemented with 10 $\%$ FCS, $50 \mu \mathrm{g} / \mathrm{ml}$ gentamycin sulfate before transferring to droplets of the same supplemented medium $(5$ oocytes $/ 100 \mu l)$ and incubated in 5\% $\mathrm{CO}_{2}$ incubator for $48 \mathrm{~h}$. Fertilization was indicated by the appearance of the second polar body and confirmed by cleavage of the oocytes to 2-4 cells after $48 \mathrm{~h}$ of insemination (Hensleigh and Hunter, 1985).

\section{In vitro culture}

Embryo culture took place in supplemented TCM-199 under mineral oil in a humified atmosphere of $5 \% \mathrm{CO}_{2}$ at $39^{\circ} \mathrm{C}$ (Hammam, et al., 1997) for 7 successive days with change of the medium every $48 \mathrm{~h}$. Cleavage was assessed after $72 \mathrm{~h}$ of culture and the number of embryos developing to the morula and blastocyst stages was assessed on 6-7 days (Saeki et al., 1990).

\section{Statistical analysis}

Data were analyzed by chi-square analysis (Snedecore and Cochran, 1980).

\section{RESULTS}

The results of the present study (Table 1 and Fig.1, 2) revealed that the percentages of post thawing morphologically normal vitrified mature oocytes were significantly higher $(\mathrm{P}<0.05)$ than that of vitrified immature oocytes $(70.6 \%$ vs. $55.4 \%)$.

The values of the cleavage and buffalo embryos rates for vitrified mature oocytes were significantly higher $(\mathrm{P}<0.05)$ when compared with those of vitrified immature oocytes (33\% and $10.3 \%$ vs. $13.3 \%$ and $2.6 \%$, respectively). 
Statistical analysis (Table 1) revealed that the presence of significant differences in the maturation and cleavage rates $(\mathrm{P}<0.05)$ in vitrified immature oocytes than that of fresh one $(49.3 \%, 13.3 \%$ vs. $81.2 \%, 41.8 \%$ ).

The differences between the percentages of developed embryos for vitrified immature (Fig.3) and fresh immature oocytes was highly significant $(\mathrm{P}<0.05),(2.6 \%$ vs. $11.3 \%)$. However, the values of buffalo embryos for vitrified matured oocytes (Fig.4) were not different significantly when compared with those for the fresh immature ones $(10.3 \%$ vs. $11.5 \%)$.

Table 1: Survival rates and developmental competence of fresh and vitrified immature and mature oocytes after thawing.

\begin{tabular}{|c|c|c|c|}
\hline \multirow{2}{*}{ Criteria } & \multirow{2}{*}{$\begin{array}{l}\text { Fresh oocytes } \\
\text { (Control) }\end{array}$} & \multicolumn{2}{|c|}{ Vitrified oocytes } \\
\hline & & Immature & Mature \\
\hline $\begin{array}{c}\text { Frozen oocytes: } \\
\text { Total No. }\end{array}$ & - & 560 & 340 \\
\hline $\begin{array}{l}\text { Morphological normal } \\
\text { (Post thawing ) } \\
\text { Total No. } \\
\text { (\%) }\end{array}$ & $\begin{array}{l}- \\
-\end{array}$ & $\begin{array}{c}310 \\
55.4^{\mathrm{a}}\end{array}$ & $\begin{array}{c}240 \\
70.6^{\mathrm{b}}\end{array}$ \\
\hline $\begin{array}{c}\text { Cultured oocytes } \\
\text { Total No. }\end{array}$ & 213 & 300 & 212 \\
\hline $\begin{array}{l}\text { Matured oocytes } \\
\text { Total No. } \\
(\%)\end{array}$ & $\begin{array}{c}173 \\
81.2^{\mathrm{a}}\end{array}$ & $\begin{array}{c}148 \\
49.3^{\mathrm{b}}\end{array}$ & $\begin{array}{l}- \\
-\end{array}$ \\
\hline $\begin{array}{l}\text { Cleaved oocytes } \\
\text { Total No. } \\
(\%)\end{array}$ & $\begin{array}{r}89 \\
41.8^{a} \\
\end{array}$ & $\begin{array}{c}40 \\
13.3^{\mathrm{b}} \\
\end{array}$ & $\begin{array}{r}70 \\
33.0^{\mathrm{a}} \\
\end{array}$ \\
\hline $\begin{array}{l}\text { Embryos } \\
\text { Total No. } \\
(\%)\end{array}$ & $\begin{array}{c}24 \\
11.3^{\mathrm{a}}\end{array}$ & $\begin{array}{c}8 \\
2.6^{\mathrm{b}}\end{array}$ & $\begin{array}{c}14 \\
10.3^{\mathrm{a}}\end{array}$ \\
\hline
\end{tabular}

In the same row, the values having different superscript letters are significantly different from control at $\mathrm{P}<0.05$. 




Fig. 1: (a) Morphologically normal post thawing vitrified immature oocytes

(b) Degenerated post thawing vitrified immature oocytes.

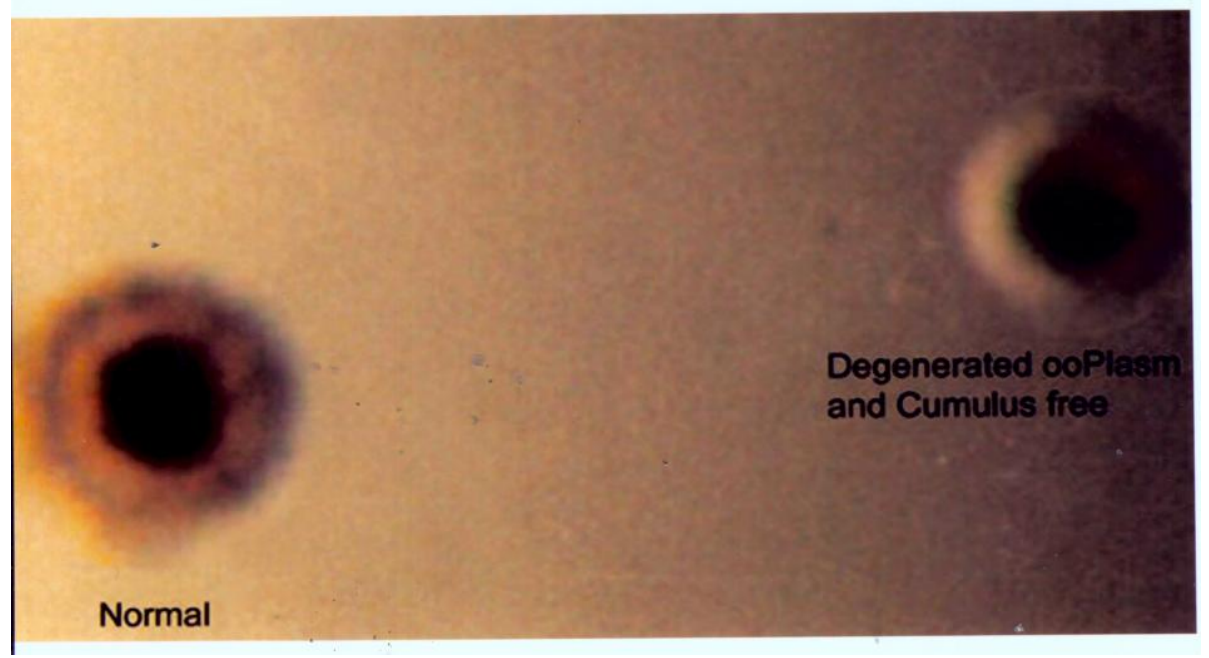

Fig. 2: Morphologically normal vitrified mature oocytes post thawing appeared and Degenerated vitrified mature oocytes post thawing. 


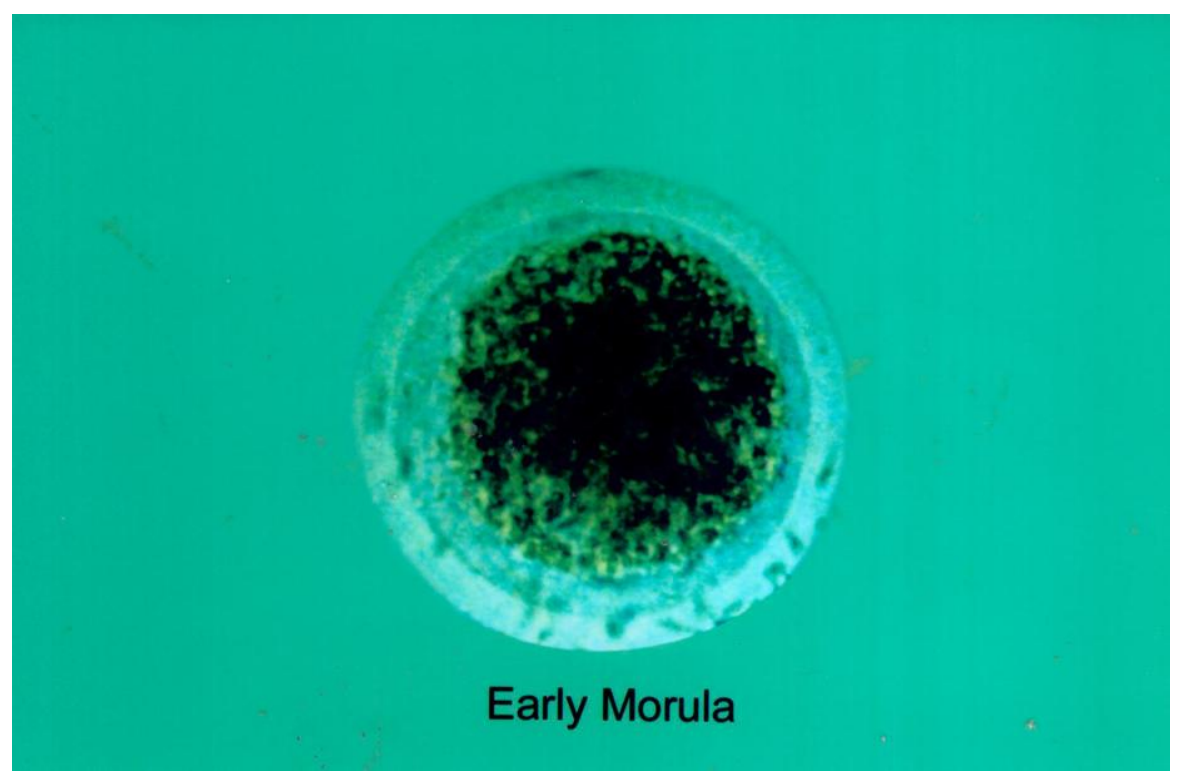

Fig. 3: Buffalo embryo obtained from vitrified immature oocyte.

\section{Compact Morula}

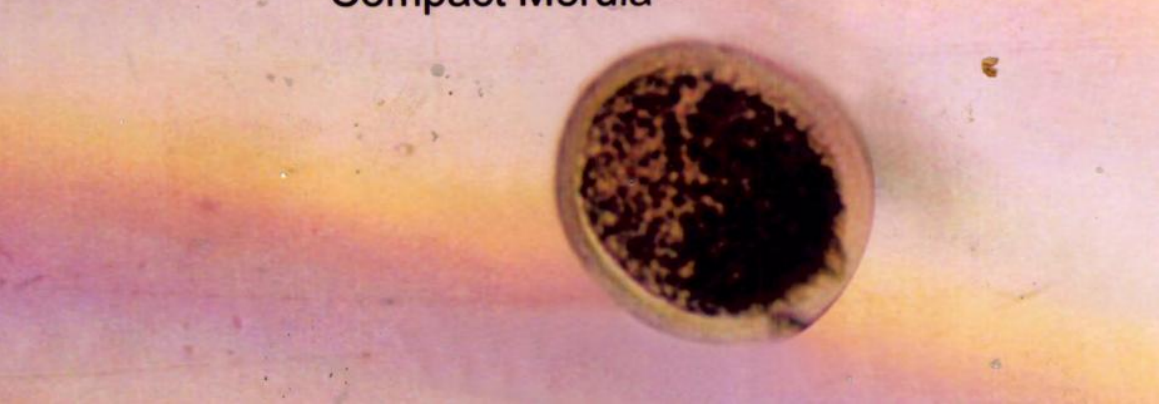

Fig. 4: Buffalo embryo obtained from vitrified mature oocyte. 


\section{DISCUSSION}

From the commercial point of view, cryopreservation technique of oocytes and embryos considered a very important factor for successful rate of embryo transferring.

The high survival rates of vitrified-thawed immature and mature buffalo oocytes observed in the present study compare favorably with other reports in which buffalo oocytes vitrified in $4.5 \mathrm{Mm}$ ethylene glycol and 3.4 Mm dimethyle sulfoxide (Dhali, et al., 1999). However, the maturation rate of buffalo oocytes in the present work in immature group was much lower after vitrification than that of fresh ones.

The proportion of post thawing morphologically normal vitrified mature oocytes were significantly higher $(\mathrm{P}<0.05)$ than that of vitrified immature oocytes $(70.4 \%$ vs. $55.4 \%)$.

A possible explanation for these results is that matured oocytes were found to be more resistant to freezing than immature ones (Fukui, et al., 1992 and Lim, et al., 1992), Moreover the hydrolyic conductivity of immature bovine oocytes is only half that of in vitro matured oocytes (Ruffing, et al., 1993) and the permeability of bovine oocytes is significantly higher for cryoprotectant after in vitro maturation (Agea, et al., 1997).

Data presented here also indicated that buffalo oocytes vitrified at the mature stage cleaved and developed into morula and blastocyst stage after thawing at a higher rate than those vitrified at the immature stage.

The freezability of immature oocytes has been reported to be low and increases as development proceeds to the blastocyst stage after fertilization (Kasai, et al., 1979 and Schroeder, et al., 1990).

The reduction in the fertilization may have resulted from disruption of the plasma membrane, extensive disorganization of the ooplasma, damage to the spindle or structural change in the zona pellucida during freezing (Carroll, et al., 1990). In addition, freezing often results in low survival of bovine oocytes because of their extreme sensitivity to temperature near $0^{\circ} \mathrm{C}(\mathrm{Wu}$, et al., 1998).

Data presented here indicated that vitrified immature buffalo oocytes developed into morula and blastocyst stage after thawing at a higher rate than those obtained by Badr, et al. (2008) who nothing had developed blastocysts. The differences between these findings may be due to IVF technique and in cryoprotectant concentration, duration of exposure to the cryoprotectant, and thawing procedure needed to be 
adapted to the given stage of oocytes in order to obtain a good survival rate.

From the present study it could be concluded that the in vitro production of buffalo embryos could be obtained from vitrified immature and mature buffalo oocytes as already carried out by Abd Allah (2003).

\section{REFERENCES}

Abd Allah, S.M. (2003): In vitro fertilization, processing and cryopreservation of buffalo oocytes and embryos. $\mathrm{Ph} \mathrm{D}$. Theriogenology, Faculty of Veterinary medicine, Cairo University (beni-suef branch).

Agea, Y.; Liu, J.; Peter, A.T.; Crister, E.S. and Crister, J.K. (1997): Cryoprotectant and water permeability of immature and in vitro matured bovine oocytes. Theriogenology, 47 (1): 340(abstract).

Badr, M.R.; Darwish, G.M. and El-Badry, D.A. (2008): Cryopreservation of immature buffalo oocytes by vitrification. Assiut Vet. Med. J., 54: 397-

Carroll, J.; Depypere, H. and Mathews, C.D.(1990): Freeze-thaw induced changes of the zona pellucida explain decreased rates of fertilization in frozen-thawed mouse oocytes. J. Reprod. Fert., 90: 547-553

Curtis, J.l. (1991): Embryo transfer procedure. Academic press, Inc, UK, PP: 30-40.

Dhali, A.; Manik, R.S.; Das, S.K.; Singla, S.K. and Palta, P. (1999): Effect of ethylene glycol concentrations and exposure time on Post-vitrification survival and IVM rate of buffalo oocytes. Theriogenology, 50: 521-530.

Fukui, E.; Kojima, T.; Shioya, Y.; Marcus, G.J. and Downey, B.R. (1992): IVF and development of frozen-thawed bovine oocytes. Cryobiology, 29: 485-492.

Ganguli, G., Indra, A. and Gupta, P. (1998): Suitability of the follicular oocytes obtained from slaughtered buffalo ovaries and assessment of their nuclear maturation. Buffalo J. 2: 217-27.

Hammam, A.M.; Zabaal, M.M. and Sabara, H.A. (1997): Effect of types of media on IVM, IVC and IVF of buffalo and cattle oocytes Beni - Suef, Vet. Med. Res., 2: 242-259. 
Hensleigh, H.C. and Hunter, A.G. (1985): IVM of bovine cumulus enclosed primary oocytes and their subsequent IVF and cleavage. J. Dairy Sci., 68: 1456-1462.

Hurtt, A.E.; Squires, E.L. and Seidel, J.R. (1999): Vitrification of equine and bovine oocytes in an ethylene glycol, ficoll and sucrose using open pulled straws. Theriogenology, 51: 166 (abstract).

Jaakma, U.; Zhang, B.R.; Larsson, B.; Katska, L.; Rynska, B. and Smorag, Z. (1995): The effect of different capacitation media on the in vitro fertilizability of bull spermatozoa. Anim. Reprod. Sci., 44: 23-31.

Kajihara, Y.; Kometani, N.; Shitanaka, Y.; Saito, S.; Yamaguchi, Y.; Hishiyama, K. and Endo, M. (1992): Pregnancy rates and births after the direct transfer of frozen-thawed bovine IVF embryos. Theriogenolgy, 37, 233 (abstract).

Kasai, M.; Kmi, J.H.; Takakamo, K.; Isudera, H.; Sakurai, T. and Machida, T. (1979): A simple method for mouse embryo cryopreservation in a low toxcity vitrification solution, without appreciable loss of viability. J. Reprod. Fertil., 89: 91-97.

Lim, J.M.; Fuki, Y. and Ono, H. (1992): Developmental capacity of bovine oocytes frozen at various maturation stages followed by I VM and IVF. Theriogenology, 37: 351-361.

Martinez, A.G.; Brogliatti, G.M. and Lagomarsino, H.R. (1999): Comparison of one step methods for freezing bovine embryos Theriogenology, 51: 145.

Nandi, S.; Ravindranatha, B.M.; Gupta, P.S.P. and Sarma, P.V. (2002): Timing of sequential changes in cumulus cells and first polar body extrusion during in vitro maturation of buffalo oocytes. Theriogenology, 57: 1151-1159.

Niemann, H. (1991): Cryopreservation of ova and embryos from livestock: current status and research needs. Theriogenology 35: 109-123.

Ruffing, N.A.; Steponkus, P.L.; Pitt, R.E. and Park, J.E. (1993): Osmotic behavior, hydorolyic conductivity and incidence of intracellular ice formation in bovine oocytes at different developmental stages. Cryobiology, 30: 562-580.

Saeki, K.; Hoshi, M.; Leibfried-Rutledge, M.L. and First, N.L. (1990): IVF and development of bovine oocytes matured with commercially available Follicle stimulating hormone. Theriogenology, 43: 1035-1039. 
Schroeder, A.C.; Champlin, A.K.; Mobraatin, I.E. and Eppig, J.J. (1990): Developmental capacity of mouse oocytes cryopreserved before and after maturation in vitro. J. Reprod. Fertil., 89: 43-50.

Snedecor, G.W. and Cochran, W.F. (1980): Statistical methods. $7^{\text {th }}$ Ed. Ames. Iowa State University Press.

Totey, S.M.; Pawshe, C.H. and Singh, G. (1993): In vitro maturation and fertilization of buffalo oocytes (Bubalus bubalis): Effect of media, hormones and sera. Theriogenology, 39: $1153-71$.

Wu, B.; Tong, J. and Leibo, S.P. (1998): Effect of chilling bovine germinal vesicle stages oocytes on formation of microtubules and the miotic spindle. Theriogenology, 49: 1:177 (abstract). 